[Primer premio de la II Olimpiada de Filosofía de Málaga organizada por FICUM, sección: segundo de bachillerato]

\title{
La libertad desde la filosofía
}

Freedom from philosophy

\author{
NATALIE TETENES y ANDREA CANTERO \\ Colegio Patrocinio San José de Estepona (España)
}

\begin{abstract}
RESUMEN
En este trabajo se trata el tema de la libertad desde el punto de vista de los diferentes ámbitos de la filosofía.

PALABRAS CLAVE

LIBERTAD, FILOSOFÍA, SOCIEDAD, POLÍTICA, RELIGIÓN, DETERMINISMO, ESCLAVITUD.
\end{abstract}

\begin{abstract}
In this paper we discussed the issue of freedom is from the point of view of the various areas of philosophy.

KEY WORDS

FREEDOM, PHILOSOPHY, SOCIETY, POLITICS, RELIGIÓN, DETERMINISM, SLAVERY.
\end{abstract}

Claridades. Revista de filosofía, 6 (2014), pp. 17-24.

ISSN: 1889-6855 ISSN-e: 1989-3787 Dl.: PM 1131-2009

Asociación para la promoción de la Filosofía y la Cultura (FICUM) 


\section{INTRODUCCIÓN}

Comenzaremos dando una breve descripción de la filosofía en la sociedad actual.

En la actualidad, y podríamos decir a nivel global, la filosofía no despierta gran entusiasmo, especialmente entre los más jóvenes. La gente de a pie no dispone de tiempo, y a veces de energía, para pararse a pensar acerca de los grandes problemas o interrogantes que acechan al hombre, algunos desde el mismo principio de éste. Problemas como establecer qué es justicia o interrogantes como el muy famoso "¿quiénes somos?". Sin embargo, nuestra sociedad lleva intrínsecas algunas ramas de la filosofía hasta tal punto que las consideramos algo natural y obvio, no reparamos en que forman parte de una importante y antigua ciencia como es la filosofía. Este es el caso de la ética o de la política. Incluso la religión estuvo ligada en algún momento, tiempo atrás, a la filosofía. De este modo, resulta innegable que la filosofía forma parte de nuestro día a día y de nosotros, nos pertenece desde el primer momento en el que el hombre comenzó a pensar, y es absurdo intentar evitarla o dejarla a un lado.

Por lo tanto, y al ser la filosofía una pieza clave de nuestro mundo, trataremos la libertad en cuanto a las relaciones sociales se refiere, haciendo referencia a la ética, ya que es la vertiente de la filosofía que actúa sobre la sociedad; y hablaremos, también, de ciertos problemas que existen en la actualidad referentes a la sociedad.

En segunda instancia, tocaremos la religión, ya que está fue, una vez, parte esencial de la filosofía, tratada por grandes filósofos y teólogos como Tomás de Aquino o San Agustín. Incurriremos en las sectas, así como en la creencia de la existencia de lo predeterminado.

A continuación se presentará la política como otra componente fundamental y de gran importancia en la sociedad de la filosofía. Dentro de este tema se hablará de la esclavitud como forma de negación de la libertad, del mismo modo que se hará referencia a la guerra en cualquiera de sus versiones.

En último lugar, se ofrecerán varias conclusiones referentes a los distintos temas desarrollados a lo largo del trabajo, esperando esclarecer y definir el tema del mismo: la contribución de la filosofía a la libertad. 


\section{SOCIEDAD}

Un ejemplo importante de la filosofía dentro de nuestra sociedad actual son las cuestiones éticas, es decir, cómo debemos actuar ante cualquier situación. Según Aristóteles, el hombre es un animal racional social, sus pautas de comportamiento deben regirse de acuerdo con ciertos criterios; según Kant, el hombre debe regirse por la competencia de la ética, utilizando las tres formulaciones de su imperativo categórico; según platón, el hombre debe regirse por de los sistemas jurídicos y políticos sobre los que se asientan nuestros derechos y deberes, en el que se incluye nuestra condición de individuos libres, a pesar de que lo jurídico no siempre sea justo.

Finalmente, otro ejemplo muy relevante en la actualidad es la noción de belleza en el contexto de una preocupación por la estética emergente. De esto podemos desprender la existencia de una gran preocupación por la estética que da lugar a debates sobre las formas de comprender y asumir nuestra condición humana. Este es un grave problema en la actualidad, en los que salen perjudicados mayoritariamente los adolescentes. Esta preocupación por la imagen, ha desembocado en muchas enfermedades como la bulimia, la anorexia, etc. es decir, todo tipo de enfermedades relacionados con el trastorno alimenticio para así poder sentirse "bien" con uno mismo. Hay personas que no saben cómo afrontar dicha preocupación llevándolo al extremo, llegando incluso a quitarse la vida. Este problema es generado por la sociedad, por haber creado un "perfil" de persona bella a la cual se le da mayor prestigio que a otra que no cumpla el perfil. Estas personas están sometidas a una presión social, la cual les provocaban cierto trastorno psicológico y limita su libertad. Al decir limitación de libertad, nos referimos a que uno no llega a ser del todo libre a ya que no pueden llegar a ser ellos mismos, es decir, se ven sometidos a un estrés y complejo constante que les hace consumirse en él poco a poco y que no les deja vivir en tranquilidad, como si estuviesen en una burbuja de la cual no encontrasen la salida. Es entonces cuando comienzan a plantearse preguntas como, ¿De qué me sirve ser quien soy si al fin y al cabo me van a juzgar por lo que soy y no por quién soy?, ¿Para qué vivir si ya no me quedan ganas?, ¿Quererme un poco más?¿Para qué si soy horrible igual ? Estos son los motivos por los que hay que aplicar la filosofía, en este caso, se pueden aplicar varias filosofías centrándose en el campo de la ética como por ejemplo la ética de Rousseau: "La libertad de uno acaba cuando empieza la de otro"; la ética 
de virtudes de Aristóteles, en la que habla de una virtud dianoética denominada prudencia, es decir, el hombre prudente es aquel que puede reconocer el punto medio en cada situación, en el caso planteado antes, el abuso hacia otras personas, uno debe analizar la situación y no llevar a cabo una acción que pueda afectar negativamente a la otra persona; también se puede aplicar la filosofía de Ricardo Yepes: "Yo no soy libre de tener una determinada constitución biopsicológica, ni de nacer en un determinado momento histórico o en cierta región, pero sí soy libre de asumirla o no en mi proyecto biográfico", con esto quiero decir que uno no debe de avergonzarse u odiarse por ser de dónde es o de quién es, uno no decide de dónde es, pero sí a dónde va, uno no decide quién es al nacer, pero sí quién puede llegar a ser; no hay que dejar en ningún momento que alguien te ponga límites, los límites sólo se los puede poner uno mismo.

Por este motivo, podemos afirmar que, en cierto modo, somos filósofos, ya que tenemos preguntas a las cuales buscamos una respuesta y hay una importante carga filosófica en nuestra definición como persona.

\section{RELIGIÓN}

Es cierto que una persona es libre de elegir sus creencias e ideologías: están los ateos, los musulmanes, los cristianos, los judíos, etc. Pero, ¿son realmente libres o se ven obligados a realizar ciertos actos bajo la presión de dicha religión? Realmente una persona nunca llega a ser libre ya que siempre se ve obligado, por circunstancias de la vida, a tener que tomar decisiones y elegir, si una persona no tiene nada que elegir significa que está muerto. Tal y como afirma Rousseau, "El hombre nace libre, pero en todas partes está encadenado", de manera que uno, a lo largo de su vida, se ve esclavo de sus decisiones tomadas en un pasado.

En el momento en que una persona elija su religión deja de ser libre, ya que de un gran abanico de posibilidades de lo que puede llegar a ser ha elegido una. Una de las religiones en la cual es escasa la libertad, es en la religión musulmana. Es cierto, que la mujer actualmente disfruta de una mayor libertad en comparación con tiempos pasados. A pesar de ello, sigue teniendo una escasa libertad. Está instaurado en el Corán que la mujer debe taparse con un burca de manera que sólo se les vean las manos, los pies y la cara, entonces es cuando uno se pregunta ¿esa mujer es realmente libre?, ¿Se pone el burca porque realmente lo quiere o porque la religión lo dicte?, hay mujeres que se lo ponen por placer, por su 
propia decisión, porque realmente les guste; otras en cambio, sólo lo hacen por miedo a lo que puedan decir de ellas o cómo se lo puedan tomar sus familiares. Este es uno de los motivos por los que esta religión no ha evolucionado, otro motivo es la situación socio-económica de los países en los que se practica el islamismo. Hay personas que afirman que la religión siempre existirá mientras exista la pobreza ya que estas personas se basan en la fe, en que todo saldrá bien, empleando expresiones como "que sea lo que Dios quiera", de este modo se sienten "seguros", piensan que así hay una pequeña posibilidad a través de la cual pueden aferrarse a la felicidad.

Una vertiente de la religión que coarta masivamente la libertad es la secta. Esta se define como el conjunto de seguidores de una doctrina religiosa o ideológica concreta que más tarde derivó en un grupo disidente que se separa de su fuente original casi siempre con connotaciones peyorativas. De estas formas de religiosidad podemos decir que consiguen reclutar a nuevos miembros para estos "clubes" religiosos mediante técnicas de extorsión o aprovechándose de la ingenuidad o vulnerabilidad de ciertas personas, a las cuales es fácil manipular. De este modo, queda claro por qué este tipo de "pseudo-religión" limita la libertad de las personas, ya que, desde el primer momento, se recurre a engaños y trucos para conseguir nuevos adeptos o, incluso, contribuciones monetarias.

Aquellas personas que creen en el destino opinan que todo en el mundo está predestinado, que el motor del universo es una inteligencia que ya ha establecido lo que ocurrirá en el futuro. Estas personas afirman que no somos dueños de nuestros actos y que no podemos controlar nuestra vida. Absolutamente todo lo que nos ocurre es fruto del destino y no podemos remediarlo, porque así está establecido por fuerzas superiores a nosotros. Por tanto, los hombres no somos libres puesto que no podemos tomar decisiones sobre nuestra vida. No somos capaces de controlar nuestros pasos ni cambiar el rumbo cuando se nos antoje, somos meras marionetas dentro de nuestras propias vidas. El filósofo español Arturo Cadenas explica, a este efecto, que la felicidad del hombre reside en trazar un proyecto de vida, lo que resultaría del todo imposible si existiera el destino. La felicidad, por tanto, reside en la libertad del hombre de tomar sus propias decisiones. 


\section{POLÍTICA}

Si consideramos la libertad desde la política, podemos decir que una persona deja de ser libre en el momento en que se le trata de manera desigual, se le considera inferior o se violan sus derechos inalienables.

Uno de los casos en los que se coarta la libertad del hombre es mediante la esclavitud. Comenzaremos ofreciendo una breve definición: La esclavitud, como institución jurídica, es una situación por la cual una persona es propiedad de otra. Se remonta a la Edad Antigua, aunque no de forma equivalente en todas las civilizaciones.

A lo largo de la historia, podemos encontrar una vertiente filosófica pro-esclavista, integrada por grandes filósofos como Aristóteles o John Locke.

Aristóteles recoge, en sus textos, pensamientos opuestos a los suyos de sus contemporáneos, a partir de los cuales expresa sus propias ideas en relación con la esclavitud. En uno de estos textos, Aristóteles iguala la esclavitud a la domesticación de animales, atribuyendo este fenómeno de subyugación a la propia naturaleza. Sin embargo, opina que la esclavitud no procedente de la naturaleza, es decir, la esclavitud de los vencidos en la guerra es ilegal e injusta.

Agustín de Hipona habla también de este fenómeno en La ciudad de Dios, en la que expresa su opinión de que es preferible la esclavitud que la subyugación a una pasión. También afirma que aquella ley que permite la esclavitud es aquella que busca mantener el correcto orden de la sociedad.

La principal argumentación de Tomás de Aquino sobre la esclavitud se deriva de su consideración de los textos de Aristóteles e Isidoro de Sevilla. Concluye que la servidumbre entendida desde un punto de vista absoluto no es natural, sin embargo, aquella servidumbre que sea útil tanto para el amo como para el esclavo, sí lo es.

John Locke, por su parte, en su Ensayo sobre el gobierno civil, desarrolla su idea de la esclavitud como una dilatación de la condena a muerte del esclavo debido a alguna falta, en cuyo caso el amo podrá utilizarlo para su propio servicio tanto como le sea útil. La esclavitud es, por tanto, la situación en la que el amo tiene poder sobre la vida de su siervo.

Podemos ver, por lo tanto, que a lo largo de la historia se ha defendido fervientemente la esclavitud, desarrollando una gran diversidad de justificaciones. 
En la actualidad, sin embargo, las grandes instituciones que persiguen la paz e igualdad tachan la esclavitud de injusta, ilegal y, según el país, anticonstitucional. A pesar de esto, de la entrada en vigor de la Convención sobre la Esclavitud, firmada en Ginebra el 25 de septiembre de 1926, y de estar 'oficialmente prohibida' en casi todos los países, la esclavitud sigue existiendo a gran escala. Como es el caso de Mauritania, la Selva Amazónica o Sudán, donde no se controla ni pena la esclavitud en su estado original o los casos de mano de obra infantil en China o de explotación sexual por todo el mundo.

Otra gran forma de violación de la libertad se da durante las guerras. Estas impiden que las personas puedan llevar su vida cotidiana, extienden el miedo y el caos y protagonizan cruentas escenas de violencia contra civiles inocentes. En algunos casos, las guerras civiles acaban con la imposición de un régimen dictatorial, restringiendo de forma prolongada las libertades de los hombres, en todos los ámbitos posibles: pensamiento, expresión, reunión, etc.

Clausewitz habla sobre la naturaleza de la guerra, así como su teleología y estrategia militar en su obra De la guerra. En ella defiende la guerra como instrumento para alcanzar un objetivo político, y ve un absurdo lógico en moderar la actividad bélica. Rousseau habla, por el contrario, de la guerra como algo ajeno al hombre, surge de una relación entre Estados, en la que el hombre no participa. Siendo esto así, ¿qué base lógica alberga que el hombre luche y se subyugue a la obediencia y defensa de una causa de la que él no ha tomado parte?

\section{CONCLUSIONES}

De los temas desarrollados en este trabajo, podemos extraer las siguientes conclusiones.

En lo referente a la ética y su actuación en la sociedad, podemos decir que se trata de un componente fundamental y de extraordinaria importancia de la filosofía. Sin ética la sociedad sería un caos, y carecería de normas lógicas. El mundo carecería del concepto de lo moralmente correcto y, en definitiva, seríamos un poco menos humanos. El hombre debe desarrollar una ética justa, que tenga en cuenta los intereses y necesidades de todos y cada uno de los integrantes de las diferentes sociedades y que actúe en favor de una justicia que busque proteger a los más débiles y denunciar lo moralmente incorrecto e injusto. 
De la reflexión sobre la religión y sus derivados se extrae la idea de que la teología, que durante tanto tiempo ha estado vinculada a la filosofía, debe hacerse eco de la idea universal de libertad. Este es un tema de gran controversia, ya que no se pueden modificar los dogmas de fe. Sin embargo, quizá sería hora de revisar ciertas interpretaciones de estos, y ajustarlos a las necesidades, problemas y características de la sociedad actual. De este mismo modo, se debería controlar la acción de aquellos que, utilizando el nombre de la religión, buscan obtener provecho de algo tan puro y humilde como la religiosidad de las personas.

La política es, también, una vertiente de grandísima importancia en nuestros días. La vemos en todas partes: en los periódicos y telediarios no dejan de hablar sobre los grandes políticos que mueven nuestro mundo. La política es una forma de organizar y controlar la sociedad, ya que no todos los hombres son capaces de autogobernarse según los principios éticos, por lo que resultan necesarias unas reglas escritas que regulen la acción humana, así como un órgano que se encargue de su cumplimiento. Si se lleva a cabo una buena política, que busque el bien común y la convivencia, se perseguirá, por extensión, la libertad del hombre. Ya que esta estará protegida por unas leyes de obligado cumplimiento.

NAtalie Tetenes y Andrea Cantero son estudiantes de bachillerato del colegio Patrocinio de San José, en Estepona (Málaga). Siendo su profesora PALOMA GArCía BRIONES.

\section{Lineas de investigacion:}

Estudiante de bachillerato

Publicaciones recientes:

Dirección electrónica: cc.andrea@hotmail.com ; Natalie.tetenes@gmail.com 